\title{
NOTA INTRODUTÓRIA À TRADUÇÃO DA SINOPSE DO DIRITTO UNIVERSALE DE GIAMBATTISTA VICO*
}

\author{
Humberto Guido**
}

\section{A Filosofia do Direito na obra de Vico}

Em junho de 1720 o filósofo italiano Giambattista Vico (1668-1744) publicou a Sinopse do Diritto Universale, anunciando o seu projeto editorial de maior expressão até então, composto de três livros: De universi iuris uno principio et fine uno (1720); De constantia Iuriprudentis (1721) e Notae in duos libros (1722). A responsabilidade do autor era grande, pois, na década anterior, ele também havia prometido uma obra de natureza filosófica composta de três livros, a De antiqüíssima italorum sapientia ex linguae latinae originibus eruenda, idealizada em três livros, nesta ordem: o metafísico, o físico e o moral. Apenas o livro metafísico foi publicado e passou a ser identificado pelo título da obra. Depois de tanto tempo, ainda não é possível afirmar com segurança o motivo para $\mathrm{o}$ abandono do projeto original; talvez a falta de recursos próprios e a ausência de um patrocinador para o seu trabalho - fato que mais tarde voltaria a se repetir no momento da publicação da obra maior, a Scienza nuova de 1725. Deste episódio o que se tem, efetivamente, é o depoimento do próprio Vico registrado em sua Vita (1728):

Mas o descontentamento com as etimologias gramaticais, que havia começado a se manifestar em Vico, era um indício daquilo

\footnotetext{
* Este trabalho foi realizado durante a vigência da Bolsa de Pesquisa para PósDoutorado (PDS).

** Pesquisador do CNPq. Professor Associado do Departamento de Filosofia e do Programa de Pós-Graduação em Filosofia da Faculdade de Artes, Filosofia e Ciências Sociais (FAFCS) da Universidade Federal de Uberlândia (UFU). E-mail: humguido@pq.cnpq.br
} 
que depois, nas últimas obras, descobriu nas origens das línguas, extraído de um princípio de natureza comum a todas, sobre o qual estabelece os princípios de uma etimologia universal para dar as origens de todas as línguas mortas e vivas. ${ }^{1}$

Naquele momento, Vico abandonou o formalismo dos estudos lingüísticos que incidiam sobre as obras de erudição, especialmente as inscritas no âmbito dos estudos jurídicos. O emprego da razão histórica foi a grande descoberta a que se refere Vico na citação acima. A obra jurídica é o resultado da ruptura com a Metafísica clássica, deixando para trás o tratamento em abstrato da natureza humana, sem que a existência, tanto das nações quanto dos indivíduos fossem consideradas nos discursos sobre o homem. Durante a década de 1710, Vico se deteve nos pensadores políticos, dando maior atenção aos jusnaturalistas. A leitura de Grotius (1583-1645), segundo o relato autobiográfico, foi decisiva para os novos rumos das suas pesquisas sobre o direito natural das gentes, conduzidas ao lado da investigação sobre os princípios da sabedoria poética das nações bárbaras.

O mérito da obra jurídica de Vico está na fundamentação histórica do direito natural, tal intento foi executado com a análise filológica das provas históricas, neste caso o direito romano. O exercício de Vico consistiu na releitura dos cânones, cujo procedimento the permitiu purgar o texto dos acréscimos que os séculos foram introduzindo ao original. $\mathrm{O}$ expediente de Vico estava em sintonia com a cultura humanista, que se encarregou de renovar os estudos jurídicos, tendo o cuidado de recuperar os textos originais. ${ }^{2}$ O intento não tinha uma finalidade meramente erudita, a motivação, já foi dito, era a descoberta das origens do direito natural das gentes,

${ }^{1}$ Autobiografia (Vita, 1728). Turim: Giulio Einaudi Editore, 1963. p. 44.

2 "Os humanistas querem, antes de mais nada, apagar do direito romano tradicional todos os acréscimos a ele feitos pela Idade Média”. VILLEY, M. A formação do pensamento jurídico moderno. Tradução de Cláudia Berliner. São Paulo: Martins Fontes, 2005. p. 550.

Educ. e Filos. Uberlândia, v. 23, n 45, p. 303-310, jan./jun. 2009. 
que não resultasse apenas das conjeturas plausíveis como havia feito Hobbes (1588-1674) ao descrever o estado de guerra como estado de natureza, ou, a situação necessária para se justificar o pacto de legitimação do Estado no presente, motivo pelo qual a História é desprezada, pois, o que interessa ao filósofo político é a justificação "do projeto político da sociedade burguesa". ${ }^{3}$

As pesquisas filológicas realizadas para a composição do Diritto Universale permitiram lograr algo mais abrangente, que não ficou restrito à ciência jurídica e que poderia ser aplicado às disciplinas que durante os séculos XVI e XVII foram refutadas pela nova ordem científica. Os novos princípios do direito natural lançaram novas luzes sobre os domínios reunidos sob o nome de Humanidades, trazendo-as para o escopo moderno. A razão histórica, aludida anteriormente, se apresenta nas páginas da obra jurídica como a expressão da sua teoria progressiva do desenvolvimento histórico das nações; esta tese resultou, em parte, do empenho na elaboração prévia do suporte metodológico da pesquisa social, quando Vico buscava elucidar a nova teoria da linguagem, desvencilhada do formalismo das gramáticas; para tanto, ele recorreu às provas filológicas extraídas dos mais antigos monumentos do passado, ou seja, da poesia dos tempos arcaicos ${ }^{4}$; não foi por outra razão que Vico se referiu ao direito romano como um "serioso poema", algo que soa da seguinte maneira: se os gregos tiveram Homero, os romanos tiveram a lei das XII Tábuas.

A Sinopse da obra jurídica informa a respeito da iniciativa de seu autor, não apenas de instaurar a ciência do Direito. Nos escritos

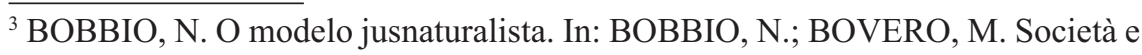
Stato nella filosofia politica moderna. Milão: Il Saggiatore, 1984. p. 54.

${ }^{4}$ De acordo com Hochstrasser, o trabalho de Vico evidencia que a linguagem é a chave para compreender que "o crescimento racional humano e a complexidade cultural emergem historicamente”. HOCHSTRASSER, T. J. Natural Law theories in the Early Enlightenment. Cambridge: Cambridge University Press, 2000. p. 10.

Educ. e Filos. Uberlândia, v. 23, n 45, p. 303-310, jan./jun. 2009. 
de 1720 Vico já antevia a possibilidade de criação da ciência social a partir da história das línguas e da história das coisas humanas ${ }^{5}$, ambas concorrendo para desvelar as origens muito remotas da sociedade civil, que até então repousavam nas conjeturas dos doutos sem que se alcançasse o seu conhecimento certo. O Direito é uma prática social que se submete a outra lógica, distinta daquela dos geômetras entretidos com a Física da natureza.

A contribuição da obra jurídica que, anos depois, foi retomada nas páginas da Scienza nuova, consiste na distinção de algo que já poderia ter sido notado: o mundo natural obedece a ordem necessária do movimento e do repouso, por isso é possível afirmar a existência de uma regularidade que ultrapassa a incapacidade humana de enxergar a harmonia para além do caos aparente. As ações humanas não se submetem à esta razão a priori, elas nascem unicamente das vontades humanas, que não se atêm à verdade transcendental e somente se detêm no certo das leis. No lugar da enunciação das leis universais peculiares às ciências naturais, a ciência jurídica se ocupa da autoridade do arbítrio humano, cujo padrão é determinado pela ordem social. No lugar da regularidade vislumbrada pelos físicos, o jurista percebe a coerência das leis, que estão em conformidade com a ordem das coisas humanas. No primeiro livro da obra jurídica, o De uno, Vico se deteve na discussão do direito natural das gentes, restando ao segundo livro, o De const., a demonstração da coerência da jurisprudência.

\footnotetext{
${ }^{5}$ Mais uma vez a leitura de Hochstrasser é elucidativa: "Vico também compartilhava da convicção de que todo fenômeno social é simultaneamente produto da vontade humana (auctoritas) e reflexo de modelos que perpassam toda a história humana: sociedade humana e imposição política sobre o mundo formavam uma lógica interna consistente tal como a linguagem era compreensível como estrutura lógica para além da aparente aplicação arbitrária e individual das convenções lingüísticas". HOCHSTRASSER, T. J. Op. cit., p. 8.
} 


\section{A tradução da Sinopse do Diritto Universale}

A tradução apresentada aqui está vinculada ao projeto de tradução integral da obra jurídica de Vico, uma atividade de longo prazo e que demanda rigor filológico e domínio conceitual da ciência jurídica. O texto da Sinopse foi escrito em italiano, diferente dos três livros que compõem a obra jurídica, todos eles redigidos em latim, tendo sido a última obra na qual Vico se serviu da língua latina. $\mathrm{Na}$ Sinopse consta, basicamente, a resenha do primeiro livro, o De uno, deixando o livro segundo, o De const., apenas na menção à extensão da obra. Mesmo não contemplando a totalidade da obra, a notícia literária de junho de 1720 é instrutiva e contribui para dar a dimensão da investigação empreendida, que pretendeu demonstrar o direito natural servindo-se da história das línguas e da história das coisas humanas.

O expediente de Vico não se confunde com a mera cronologia dos eventos históricos de Roma; quando é necessário ilustrar a sua tese com a história do direito, os eventos evocados oferecem a razão - o ius - das práticas sociais dos antigos, evidenciando assim, a formação da sociedade civil, primeiro com as famílias e, depois, com as primeiras repúblicas aristocráticas. A origem de Roma é semelhante ao que ocorreu em outras regiões do mundo antigo, o que confirma a natureza comum das nações.

As peculiaridades das construções lingüísticas de Vico evidenciam o uso do italiano arcaico, algo peculiar, porque é distinto das conversações e do estilo rebuscado dos glosadores do direito romano. A tradução portuguesa procurou ser fiel ao original e manteve certas asperezas contidas em alguns parágrafos, pois o autor as considerava úteis para demonstrar a unidade do pensamento, possível de ser obtida quando o pesquisador confronta a história das línguas com a história das coisas.

No texto traduzido há alguns colchetes que servem para melhor compreender certos termos empregados por Vico no lugar de palavras

Educ. e Filos. Uberlândia, v. 23, n 45, p. 303-310, jan./jun. 2009 . 
mais fáceis do que aquelas presentes no escrito introdutório. Ocorre também do colchete servir para introduzir ou reintroduzir um termo que havia sido empregado há pouco, ou que não consta do período, mas que o leitor de Vico é capaz de identificá-lo mesmo não constando da redação. Na versão portuguesa há também as notas do tradutor que se viu na obrigação de informar o leitor a respeito de algumas referências a nomes da mitologia grega e romana menos conhecidos do que aqueles mais freqüentes. As notas se aplicaram também para os esclarecimentos relativos ao emprego das expressões jurídicas que remontam ao direito romano antigo. Em suma, as notas foi o expediente adotado para auxiliar o leitor na compreensão da finalidade da obra jurídica e para oferecer esclarecimentos pontuais; não há nenhuma identificação nas notas ou nos colchetes, o que costumeiramente é feito com o recurso N.T. (Nota do Tradutor), pois, na Sinopse não comparecem estes colchetes e estas notas, ficando, desde já, ciente o leitor de que estes acréscimos, facilmente identificados, são de autoria do tradutor. Porém, há no texto alguns parênteses, este sim, são originais e foram utilizados pelo próprio Vico.

Na execução da versão portuguesa da Sinopse em me servi das edições italianas disponíveis: a de Fausto Nicolini' e a de Paolo Cristofolini ${ }^{7}$. O manuseio da edição de Nicolini foi, predominante, a obra jurídica de Vico, editada em três tomos, sendo que a Sinopse e o De uno constam do primeiro tomo. A edição de Cristofolini, também muito útil, serviu para dirimir as dúvidas e para auxiliar nas escolhas etimológicas, quando o texto italiano de Vico impunha alguma dificuldade para encontrar correlato idiomático no italiano moderno.

Por fim, mas não por último, reitero os meus agradecimentos ao Conselho do Departamento de Filosofia da Universidade Federal de Uberlândia pela liberação para a realização do estágio de Pós-Doutorado no período de agosto de 2007 a outubro de

${ }^{6}$ Il diritto universale. Bari: Laterza, 1936.

${ }^{7}$ Opere giuridiche. Florença: Sansoni, 1974.

Educ. e Filos. Uberlândia, v. 23, n 45, p. 303-310, jan./jun. 2009. 
2008. Agradecimento idêntico é dirigido ao Departamento de Filosofia da Faculdade de Filosofia, Letras e Ciências Humanas da USP que acolheu a minha proposta de trabalho, tendo em vista o cumprimento das atividades do estágio de Pós-Doutorado. O sincero agradecimento a Prof. ${ }^{a}$ Dr. ${ }^{a}$ Maria das Graças de Souza pela tutoria e também pela amizade, dando-me um voto de confiança para o andamento da tradução da obra jurídica de Vico. A minha gratidão ao Prof. Dr. Fabrizio Lomonaco da Universidade dos Estudos Federico II de Nápoles, que, além da cordialidade no esclarecimento de minhas dúvidas, me fez chegar a edição do De uno feita a partir da reprodução em fac-símile do texto original de 1720. Dentre tantos auxílios, eu devo ao CNPq o patrocínio das atividades de tradução da obra jurídica que me foi concedido, inicialmente, com a bolsa de Pesquisa (PDS) e, depois, com a aprovação do Projeto de Pesquisa no Edital CNPq/MCT 03/2008 para as Ciências Humanas, Sociais e Sociais Aplicadas. 
